\title{
Prevalence and nature of psychiatric disorders in geriatric people attending psychiatry outpatient department
}

\author{
Poudel $\mathbf{R}^{1}$, Belbase $\mathbf{M}^{2}$ \\ 1. Assistant Professor, Department of Psychiatry, Nepalgunj Medical College, Kohalpur, Nepal 2. \\ Associate Professor, Department of Psychiatry, Nepalgunj Medical College, Kohalpur, Nepal
}

E-mail *Corresponding author : reet.poudel@gmail.com

\begin{abstract}
Introduction: Geriatric population is growing faster than all younger age groups. More than $20 \%$ of the geriatric people suffer from a mental or neurological disorder. Various studies have been conducted in Nepal related to mental and neurological disorders in geriatric people including epidemiological survey, outpatient department (OPD) based studies and inpatient studies. The aim of the present study was to determine the prevalence and nature of psychiatric disorders in geriatric subjects

Material And Method: Geriatric subjects attending outpatient department of psychiatry, Nepalgunj Medical College Teaching Hospital (NGMCTH), Kohalpur, Nepal from January to August 2018 (8 months) were enrolled for the study. Ethical clearance was obtained from the Institutional Review Committee of the NGMCTH and written consent was taken from the subjects or next to kin. Socio-demographic profile and other details of the subjects were obtained. Diagnosis was made using the ICD 10. Data was analyzed using Statistical Package for the Social Sciences (SPSS) version 21.0 for Windows.

Results: The prevalence of psychiatric disorders in geriatric subjects was $6.25 \%$. The mean age of the subjects was $68.6 \pm 7.39$ years. Female constituted $51.1 \%$ of the subjects while male $48.9 \%$. Category wise, mood disorders was the most common diagnosis (44.9\%) followed by organic disorders $(20.2 \%)$ and neurotic disorders $(12.9 \%)$ respectively. Mood disorders and organic disorders were significantly associated with the age of the subjects $(p<0.05)$. Disorder wise, depression was the most common diagnosis $(39.9 \%)$ followed by dementia $(12.4 \%)$ and anxiety disorder (10.1\%) respectively. Dementia and delirium were the only disorders significantly associated with the age of the subject $(p=0.01$ ). There was no statistically significant association of individual disorders with sex of the subjects.
\end{abstract}

Conclusion: Depression, dementia and anxiety disorder was the most common diagnosis in geriatric people.

Keywords: Geriatric, Elderly, Psychiatric Disorder, Nepal

\section{INTRODUCTION}

Worldwide, geriatric population (60 years and above) is growing faster than all younger age groups. Compared to 2017, the number of persons aged 60 or above is expected to be more than double by 2050 and more than triple by 2100, rising from 962 million in 2017 to 2.1 billion in 2050 and 3.1 billion in $2100 .{ }^{1}$ Similar to the global scenario, geriatric population has been increasing in Nepal since 1991, and in 2011 it constituted $8.13 \%$ of the total population of Nepal. It is expected to increase by $27.08 \%$ in 2021 and again by $25.23 \%$ in 2031 to compromise $10.20 \%$ of the total national population. ${ }^{2}$

The prevalence of mental disorders is high among the elderly. ${ }^{3-5}$ More than $20 \%$ of the geriatric people suffer from a mental or neurological disorder (excluding headache disorders) and $6.6 \%$ of all disability among them is attributed to mental and neurological 
disorders. Dementia and depression are the most common mental and neurological disorders in this age group, which affect approximately $5 \%$ and $7 \%$ of the world's older population, respectively. ${ }^{6}$ As the geriatric population is rising all over the world, it expected to increase the burden of mental and neurological disorders in this age group in the coming future.

Various studies have been conducted in Nepal related to mental and neurological disorders in geriatric people including epidemiological survey $^{7}$, outpatient department (OPD) based studies ${ }^{8-11}$ and inpatient studies. ${ }^{12}$ The aim of the present study was to determine the prevalence and nature of psychiatric disorders in geriatric subjects attending psychiatry OPD and to examine the relationship of various psychiatric disorders with the age and sex of the patient.

\section{MATERIAL AND METHOD}

The present study was conducted at Department of Psychiatry, Nepalgunj Medical College Teaching Hospital (NGMCTH), Kohalpur, Nepal. The duration of the study was eight months, from January to August 2018. Ethical clearance was obtained from the Institutional Review Committee of the NGMCTH. Subjects aged 60 years and above visiting the psychiatry OPD were explained about the study and written consent was taken from them or next to kin. Socio-demographic profile and other details of the subjects were obtained. Psychiatry diagnosis was made using the ICD $10 .{ }^{13}$ Data was analyzed using Statistical Package for the Social Sciences (SPSS) version 21.0 for Windows.

\section{RESULT}

During the period of 8 months, 2847 subjects visited psychiatry OPD among which 178 were in geriatric age group. The prevalence of geriatric subjects attending psychiatry OPD was $6.25 \%$. The mean age of the subjects was $68.6 \pm$ 7.39 years. Table 1 shows the socio-demographic characteristics of the subjects. Female constituted $51.1 \%(\mathrm{n}=91)$ of the subjects while male $48.9 \%(\mathrm{n}=87)$. Majority of the subjects were married $(75.3 \%)$, Hindu (95.6\%), from rural domicile $(53.9 \%)$ and with no education $(75.3 \%)$.
Table 1: Subjects Respondents' Sociodemographic Characteristics ( $n=178)$

\begin{tabular}{|l|l|l|l|}
\hline \multicolumn{2}{|l|}{ Characteristics } & Frequency & Percentage \\
\hline \multirow{4}{*}{ Sex } & Male & 87 & $48.9 \%$ \\
\cline { 2 - 4 } & Female & 91 & $51.1 \%$ \\
\hline \multirow{4}{*}{$\begin{array}{l}\text { Marital } \\
\text { status }\end{array}$} & Never married & 4 & $2.2 \%$ \\
\cline { 2 - 4 } & Married & 134 & $75.3 \%$ \\
\cline { 2 - 4 } & Widow/Widower & 37 & $20.8 \%$ \\
\cline { 2 - 4 } & $\begin{array}{l}\text { Separated/ } \\
\text { Divorcee }\end{array}$ & 3 & $1.7 \%$ \\
\hline \multirow{3}{*}{$\begin{array}{l}\text { Place of } \\
\text { Residence }\end{array}$} & Urban & 80 & $44.9 \%$ \\
\cline { 2 - 4 } & Rural & 96 & $53.9 \%$ \\
\cline { 2 - 4 } & India & 2 & $1.1 \%$ \\
\hline Religion & Hindu & 170 & $95.6 \%$ \\
\cline { 2 - 4 } & Muslim & 4 & $2.2 \%$ \\
\cline { 2 - 4 } & Christian & 4 & $2.2 \%$ \\
\hline Education & No education & 134 & $75.3 \%$ \\
\cline { 2 - 4 } & Some education & 44 & $24.7 \%$ \\
\hline
\end{tabular}

Table 2 shows the distribution of subjects based on age and sex. Category wise, mood disorders was the most common diagnosis $(44.9 \%)$ followed by organic disorders (20.2\%) and neurotic disorders $(12.9 \%)$ respectively. Mood disorders and organic disorders were significantly associated with the age of the subjects $(\mathrm{p}<0.05)$. Disorder wise, depression was the most common diagnosis (39.9\%) followed by dementia $(12.4 \%)$ and anxiety disorder $(10.1 \%)$ respectively. Dementia and delirium were the only disorders significantly associated with the age of the subject $(\mathrm{p}=0.01)$.

Table 3 shows distribution of subjects according to sex. There was no statistically significant association of individual disorders with sex of the subject. 
Table 2: Distribution of Subjects According to Diagnosis \& Age

\begin{tabular}{|c|c|c|c|c|c|c|c|c|}
\hline \multirow[t]{2}{*}{ Category } & \multirow[t]{2}{*}{ Diagnosis } & \multicolumn{5}{|c|}{ Age range in years(N) } & \multirow{2}{*}{$\begin{array}{l}\text { Total } \\
(\mathrm{N}, \%)\end{array}$} & \multirow{2}{*}{$\begin{array}{l}p \\
\text { value }\end{array}$} \\
\hline & & $60-64$ & $65-69$ & $70-74$ & $75-79$ & $\geq 80$ & & \\
\hline \multirow{4}{*}{ Organic disorders } & Dementia & 4 & 5 & 2 & 4 & 7 & $22(12.4)$ & $0.001^{*}$ \\
\hline & Delirium & 0 & 0 & 3 & 3 & 2 & $8(4.5)$ & $0.001^{*}$ \\
\hline & Organic Psychosis & 1 & 2 & 3 & 0 & 0 & $6(3.4)$ & 0.981 \\
\hline & Total & 5 & 7 & 8 & 7 & 9 & $36(20.2)$ & $0.000^{*}$ \\
\hline $\begin{array}{l}\text { Substance Use } \\
\text { Disorders }\end{array}$ & $\begin{array}{l}\text { Alcohol use } \\
\text { disorder }\end{array}$ & 6 & 2 & 1 & 2 & 0 & $11(6.2)$ & 0.230 \\
\hline \multirow[t]{3}{*}{ Psychotic Disorders } & Schizophrenia & 2 & 3 & 3 & 0 & 0 & $8(4.5)$ & 0.442 \\
\hline & Psychosis NOS & 2 & 4 & 3 & 0 & 0 & $9(5.1)$ & 0.569 \\
\hline & Total & 4 & 7 & 6 & 0 & 0 & $17(9.6)$ & 0.333 \\
\hline \multirow{4}{*}{ Mood Disorders } & Depression & 31 & 19 & 12 & 5 & 4 & $71(39.9)$ & 0.05 \\
\hline & Mania & 1 & 0 & 1 & 1 & 0 & $3(1.7)$ & 0.626 \\
\hline & BPAD & 0 & 3 & 2 & 0 & 1 & $6(3.4)$ & 0.419 \\
\hline & Total & 32 & 22 & 15 & 6 & 5 & $80(44.9)$ & $0.020^{*}$ \\
\hline \multirow[t]{4}{*}{ Neurotic Disorders } & Anxiety Disorder & 4 & 2 & 8 & 3 & 1 & 18(10.1) & 0.250 \\
\hline & $\begin{array}{l}\text { Somatoform } \\
\text { Disorder }\end{array}$ & 1 & 2 & 1 & 0 & 0 & $4(2.2)$ & 0.479 \\
\hline & OCD & 1 & 0 & 0 & 0 & 0 & $1(0.6)$ & 0.244 \\
\hline & Total & 6 & 4 & 9 & 3 & 1 & $23(12.9)$ & 0.645 \\
\hline \multirow[t]{4}{*}{ Other Disorders } & Epilepsy & 2 & 1 & 1 & 1 & 1 & $6(3.4)$ & 0.452 \\
\hline & ISH & 2 & 0 & 1 & 0 & 0 & $3(1.7)$ & 0.214 \\
\hline & Primary Headache & 1 & 1 & 0 & 0 & 0 & $2(1.1)$ & 0.328 \\
\hline & Total & 5 & 2 & 2 & 1 & 1 & $11(6.2)$ & 0.598 \\
\hline \multicolumn{2}{|l|}{ Grand Total } & $58(32.6)$ & $44(24.7)$ & $41(23)$ & 19(10.7) & $16(9)$ & $178(100)$ & \\
\hline
\end{tabular}

Table 3: Distribution Of Subjects According to Diagnosis and Sex

\begin{tabular}{|c|c|c|c|c|c|}
\hline \multirow[t]{2}{*}{ Category } & \multirow[t]{2}{*}{ Diagnosis } & \multicolumn{2}{|c|}{ Sex } & \multirow[t]{2}{*}{ Total } & \multirow[t]{2}{*}{ p value } \\
\hline & & Male & Female & & \\
\hline \multirow[t]{4}{*}{ Organic disorders } & Dementia & 9 & 13 & 22 & 0.427 \\
\hline & Delirium & 5 & 3 & 8 & 0.433 \\
\hline & Organic Psychosis & 3 & 3 & 6 & 0.956 \\
\hline & Total & 17 & 19 & 36 & 0.825 \\
\hline Substance Use Disorders & Alcohol use disorder & 9 & 2 & 11 & 0.103 \\
\hline \multirow[t]{3}{*}{ Psychotic Disorders } & Schizophrenia & 4 & 4 & 8 & 0.948 \\
\hline & Psychosis NOS & 4 & 5 & 9 & 0.786 \\
\hline & Total & 8 & 9 & 17 & 0.876 \\
\hline \multirow[t]{4}{*}{ Mood Disorders } & Depression & 34 & 37 & 71 & 0.831 \\
\hline & Mania & 2 & 1 & 3 & 0.537 \\
\hline & BPAD & 5 & 1 & 6 & 0.087 \\
\hline & Total & 41 & 39 & 80 & 0.570 \\
\hline \multirow[t]{4}{*}{ Neurotic Disorders } & Anxiety Disorder & 7 & 11 & 18 & 0.374 \\
\hline & Somatoform Disorder & 2 & 2 & 4 & 0.964 \\
\hline & OCD & 1 & 0 & 1 & 0.308 \\
\hline & Total & 10 & 13 & 23 & 0.581 \\
\hline \multirow[t]{4}{*}{ Other Disorders } & Epilepsy & 2 & 4 & 6 & 0.441 \\
\hline & ISH & 0 & 3 & 3 & 0.089 \\
\hline & Primary Headache & 0 & 2 & 2 & 0.166 \\
\hline & Total & 2 & 9 & 11 & $0.036^{*}$ \\
\hline Grand Total & & $87(48.88)$ & 91(51.12) & 178 & \\
\hline
\end{tabular}




\section{DISCUSSION:}

Prevalence, age-sex distribution and sociodemographic profile:

Prevalence of geriatric subjects attending psychiatry OPD was $6.25 \%$. Aich et al in an outpatient study reported an almost similar prevalence of $6.9 \%^{10}$. Nepalese OPD based studies related to psychiatry morbidity have reported 60 years and above subjects consisting of $7.6 \%$ to $11 \%$ of the total OPD attendance. ${ }^{14-16}$ In our study, male patients contributed $51.12 \%$ and female $48.18 \%$. Male preponderance was observed by Aich et $\mathrm{al}^{10}(54.5 \%)$ whereas female preponderance was reported by Shakya $(54 \%)^{11}$ and Nepal et al $(51 \%)^{17}$ in geriatric subjects visiting OPD. None of the psychiatric disorders were significantly associated with the sex of the subject. Majority of the patients (58\%) were below 70 years of age. Similar findings have been reported in other OPD based studies from Nepal.10,11,17

\section{Psychiatric morbidity:}

In our study mood disorder was the most common diagnosis category (44.9\%). In OPD based studies from Nepal, mood disorders has been reported in the range of $19.5 \% 10$ to $36.7 \% .10,17$ Shakya ${ }^{11}$ reported a much higher prevalence of mood disorders of $46 \%$ but the sample consisted of subjects aged above 55years while we included subjects 60 years and above. Study from India by Singh et $\mathrm{al}^{18}$ reported mood disorders as the most common diagnosis $(48.07 \%)$ in geriatric subjects which is in consistent with our finding. Disorder wise depression was the most common diagnosis (39.9\%). Prevalence of depression among elderly was found to be $49.4 \%$ in a community based study $\cdot{ }^{19} \mathrm{Aich}$ et $\mathrm{al}^{10}$ reported depression in $15.2 \%$ of geriatric subjects while life time prevalence of major depression in geriatric psychiatric patients was found to be $26.5 \%$ by Ritchie et al in French population. ${ }^{5}$ Our finding of depression as the most common diagnosis is in agreement with many earlier studies from Nepal.11,17

Dementia (12.4\%) was the second most common diagnosis. Studies from Nepal have shown dementia in range of $6 \%^{11}$ to $8.9 \%^{10}$ in geriatric OPD visiting patients. Organic mental disorders as a group was observed in $20.2 \%$, the value of which was similar to that reported by Koirala et al $(28 \%) .{ }^{20}$ Our study revealed anxiety disorder as the third most common diagnosis with $10.1 \%$ geriatric patients diagnosed with it. Koirala et al and Aich et al reported a similar low prevalence of anxiety disorder of $8 \%$ and $9.7 \%$ respectively. Shakya reported a higher prevalence of $22 \%$ but the disorders included not only anxiety disorder exclusively, but also phobia and obsessive compulsive disorder. Neurotic disorders as a group was observed in $12.9 \%$ of the subjects which is similar to that observed by Nepal et al $(13.8 \%)^{17}$. Singh et $\mathrm{al}^{18}$ reported $15.47 \%$ of geriatric subjects diagnosed with neurotic disorders which is consistent with our study. Aditya el $\mathrm{al}^{21}$ in a study in Kathmandu found higher prevalence of anxiety disorders $(76.1 \%)$ in geriatric patients. A different methodology employed for the study and subjects aged 65 years and more suffering from some medical illness enrolled for the study might have resulted in higher prevalence of anxiety disorder in the said study.

Psychotic disorders were observed in $9.6 \%$ of the subjects. Shakya (6\%) and Nepal et al. (6.2\%) reported a similar low prevalence of psychotic disorders in elderly whereas Aich et $\mathrm{al}^{10}$ reported a higher prevalence $(26.4 \%)$ which may have resulted due to difference in the geographical location of the conducted studies. Alcohol use disorder (AUD) was diagnosed in $6.2 \%$ of the subjects. Nepalese OPD based studies have reported AUD in range of $10.5 \%$ to $14 \% .10,11,17,22$

In our study prevalence of BPAD (including first episode mania) was $5.06 \%$. Reported prevalence of mania amongst geriatric people is found to be low $(1-2 \%)$ in both in-patient as well as community prevalence studies from western countries. ${ }^{5,23} \mathrm{Aich}$ et $\mathrm{al}^{10}$ reported prevalence of mania as $4.3 \%$ while Shakya ${ }^{11}$ reported prevalence of BPAD as $7 \%$ which is in agreement with our finding. We also reported prevalence of other disorders which frequently present to psychiatry OPD including epilepsy $(3.4 \%)$, intentional self harm or ISH $(1.7 \%)$ and primary headache $(1.1 \%)$. Nepal et al reported prevalence of headache as $1.90 \%$ which is similar to our study. Aich et $\mathrm{al}^{10}$ reported a much higher prevalence of chronic headache $(12.8 \%)$. in this age group. This discrepancy of prevalence of primary headache may be due to geographical location of the institution and due to increased awareness of other departments in 
referring headache to psychiatry. ISH has been reported in the rage of $0.95 \% 17$ to $2 \%^{11}$ in earlier Nepalese studies which is similar to our study. Depression, dementia and anxiety disorder was the most common diagnosis Category wise, mood disorders and organic disorders were significantly associated with the age of the subjects $(p<0.05)$. Dementia and delirium were the only individual disorders significantly associated with the age of the subject $(\mathrm{p}=0.01)$. In our study, we tried to determine the prevalence of psychiatric disorders in geriatric people attending psychiatry OPD and analyzed the relationship of psychiatric disorders with the age and sex of the subject. As this study was conducted in OPD attending subjects, there were some limitations that need to be addressed. First, OPD based finding cannot not be generalized to the population of the community so more community based research on this topic is warranted. Second, geriatric subjects were not accessed for any medical or surgical comorbidity which might have increased the presentation of psychiatric disorders like anxiety and depression.

\section{CONCLUSION:}

The present study found the prevalence of geriatric subjects attending psychiatry OPD to be $6.25 \%$. Depression, dementia and anxiety disorder was the most common diagnosis in geriatric people visiting psychiatry OPD.. Category wise, mood disorders and organic disorders were significantly associated with the age of the subjects $(p<0.05)$. Dementia and delirium were the only individual disorders significantly associated with the age of the subject $(p=0.01)$. There was no statistically significant association of individual disorders with sex of the subject.

\section{ACKNOWLEDGEMENT: None}

\section{CONFLICT OF INTEREST: None}

\section{REFERENCES:}

1. World Population Prospects: The 2017 Revision, Key Findings and Advance Tables. Working Paper No. ESA/P/WP/248. United Nations, Department of Economic and Social Affairs, Population Division; 2017.
2. 2015 Statistical Year Book Nepal. Government of Nepal National Planning Commission Secretariat Central Bureau of Statistics; 2016.

3. Gum AM, King-Kallimanis B, Kohn R. Prevalence of mood, anxiety, and substance-abuse disorders for older Americans in the national comorbidity surveyreplication. The American Journal of Geriatric Psychiatry. 2009 Sep;17(9):769-81.

4. Préville $M$, Boyer $R$, Grenier $S$, Dubé $M$, Voyer $P$, Punti $R$, et al. The epidemiology of psychiatric disorders in Quebec's older adult population. Canadian Journal of Psychiatry. 2008 Dec;53(12):822-32.

5. Ritchie K, Artero S, Beluche I, Ancelin M, Mann A, Dupuy $A$, et al. Prevalence of DSM-IV psychiatric disorder in the French elderly population. The British Journal of Psychiatry. 2004 Feb;184:147-52.

6. World Health Organization. Mental health of older adults [Internet]. [cited 2018 Jul 11]. Available from: https://www.who.int/news-room/factsheets/detail/mental-health-of-older-adults

7. Subedi S, Tausig M, Subedi J, Broughton CL, Williams-Blangero S. Mental illness and disability among elders in developing countries: the case of Nepal. Journal of Aging and Health. 2004 Feb;16(1):71-87.

8. Khattri JB, Nepal MK. Study of depression among geriatric population in Nepal. Nepal Medical College Journal. 2006 Dec;8(4):220-3.

9. Ghimire S, Baral BK, Pokhrel BR, Pokhrel A, Acharya $A$, Amatya $D$, et al. Depression, malnutrition, and health-related quality of life among Nepali older patients. BMC Geriatrics. 2018 Aug 24;18(1):191.

10. Aich TK, Shah S, Subedi S. Pattern of Neuropsychiatric Illnesses in Geriatric Population: An Outpatient Study Report. Journal of Psychiatrists' Association of Nepal. 4(1):12-9.

11. Shakya DR. Psychiatric morbidities of elderly psychiatry out-patients in a tertiary-care hospital. Journal of College of Medical Sciences-Nepal. 2011;7(4):1-8.

12. Aich TK, Dhungana M, Muthuswamy R. Pattern of neuropsychiatric illnesses in older age group population: an inpatient study report from Nepal. Indian Journal of Psychiatry. 2012 Jan;54(1):23-31.

13. The ICD-10 Classification of Mental and Behavioral Disorders Diagnostic Criteria for Research. Geneva: World Health Organization; 1993.

14. Shrestha MR, Pradhan S, Sharma S. Morbidity pattern of psychiatric disorders in patient seeking treatment in psychiatric OPD of private tertiary care hospital. Postgraduate medical journal of NAMS. 2011;11(1):28-33.

15. Koirala NR, Yadav R, Das AK, Poudel J, Bhagat SK. A study of socio-demographic and diagnostic profile of patients attending the psychiatric out-patient department of Nobel Medical College, Biratnagar. Journal of Nobel Medical College. 2012;1(2):45-9.

16. Khatri JB, Godar ST, Thapa P, Ramesh K, Chakrabortty PK, Thapa BB. Socio-demographic 
characteristics and diagnostic profile of patients attending psychiatric OPD of a private hospital in western region of Nepal. Nepal Journal of Medical Sciences. 2012;1(1):15-8.

17. Nepal S, Sapkota N, Kumar R, Deo BK, Mishra S. Psychiatric Disorders in Elderly Patients attending $O P D$ of Tertiary Care Centre in Eastern region of Nepal. Journal of Psychiatrists' Association of Nepal. 2016;5(1):221-6.

18. Singh GP, Chavan BS, Arun P, Lobraj, Sidana A. Geriatric out-patients with psychiatric illnesses in a teaching hospital setting - a retrospective study. Indian Journal of Psychiatry. 2004 Apr;46(2):140-3.

19. Subedi S, Shrestha P, Thapa D. Study Of Depression in Elderly: Prevalence and Factors Associated. Journal of Psychiatrists' Association of Nepal. 2018;7(2):1623.

20. Koirala NR, Mahat P, Nepal MK, Ojha SP, Sinha UK, Pokhrel A, et al. Geriatric psychiatry: sociodemographic characteristics and diagnostic profile among senior citizens attending the psychiatric outpatient department of a tertiary health care facility in Nepal. Journal of Institute of Medicine. 2000;22(3).

21. Kumar, A, Sharma SR, Timilsina S, Giri S, Yadav V. High Prevalence of Depression and Anxiety Symptoms among Hospitalized Geriatric Medical Inpatients: A study from a Tertiary Level Hospital in Nepal. University of Toronto Medical Journal. 2010;88(1):325.

22. Thapa P, Chakraborty PK, Khattri JB, Ramesh K, Sharma B. Psychiatric morbidity in elderly patients attending OPD of tertiary care centre in western region of Nepal. Industrial Psychiatry Journal. 2014;23(2):101-4.

23. Draper B. The elderly admitted to a general hospital psychiatry ward. The Australian and New Zealand Journal of Psychiatry. 1994 Jun;28(2):288-97. 